\title{
Impact of steam generator start-up limitations on the performance of a parabolic trough solar power plant
}

Ferruzza, Davide; Topel, Monika; Laumert, Björn; Haglind, Fredrik

Published in:

Solar Energy

Link to article, DOI:

10.1016/j.solener.2018.05.010

Publication date:

2018

Document Version

Peer reviewed version

Link back to DTU Orbit

Citation (APA):

Ferruzza, D., Topel, M., Laumert, B., \& Haglind, F. (2018). Impact of steam generator start-up limitations on the performance of a parabolic trough solar power plant. Solar Energy, 169, 255-263.

https://doi.org/10.1016/i.solener.2018.05.010

\section{General rights}

Copyright and moral rights for the publications made accessible in the public portal are retained by the authors and/or other copyright owners and it is a condition of accessing publications that users recognise and abide by the legal requirements associated with these rights.

- Users may download and print one copy of any publication from the public portal for the purpose of private study or research.

- You may not further distribute the material or use it for any profit-making activity or commercial gain

- You may freely distribute the URL identifying the publication in the public portal 


\section{Impact of steam generator start-up limitations on the performance of a}

\section{2 parabolic trough solar power plant}

3 Davide Ferruzza ${ }^{1}$, Monika Topel ${ }^{2}$, Björn Laumert ${ }^{2}$, Fredrik Haglind ${ }^{1}$.

$4 \quad{ }^{1}$ Department of Mechanical Engineering, Technical University of Denmark, Nils Koppels Allé, Building 5 403, 2800 Kongens Lyngby, Denmark

$6 \quad{ }^{2}$ Department of Energy Technology, KTH Royal Institute of Technology, 100 44, Stockholm, Sweden

7 *Phone number: +45 27296900, e-mail: daferr@mek.dtu.dk

\section{Abstract}

Concentrating solar power plants are an attractive option in the renewable energy generation market. The possibility of integrating relatively cheap forms of energy storage makes them a desirable solution when power generation must be readily available at any time of the day. Solar power plants typically start-up and shut down every day, so in order to maximize their profitability, it is necessary to increase their flexibility in transient operation and to initiate power generation as rapidly as possible. Two of the key components are the steam generator and steam turbine and the rates at which they can reach operational speed are limited by thermo-mechanical constraints. This paper presents an analysis of the effects of the thermal stress limitations of the steam generator and steam turbine on the power plant start-up, and quantifies their impact on the economy of the system. A dynamic model of a parabolic trough power plant was developed and integrated with a logic controller to identify start-up limitations, and subsequently the dynamic model was integrated in a techno-economic tool previously developed by the authors. The plant was analysed under two different operating strategies, namely solar-driven and peak-load. The results indicate that for steam generator hot start-ups, a $1.5 \%$ increase in peak-load electricity production would be achieved by doubling the maximum allowable heating rate of the evaporator. No useful increase would be achieved by increasing the rates beyond a limit of $7-8 \mathrm{~K} / \mathrm{min}$, as the turbine would then be the main 
24 limiting component during start-up. Similar conclusions can be drawn for the solar-driven case, for which

25 the solar field and the energy source availability would pose the major constraint when starting up the

26 steam generator system.

27 Key words: Solar Energy, Concentrating Solar Power, Parabolic Trough power plant; Steam generator;

28 Steam turbine; Start-up;

29 Nomenclature

30 ACC Air cooled condenser

31 CSPP Concentrating Solar Power plant

32 CT Cold tank

33 D Deaerator

34 ECO Economizer

35 EVA Evaporator

36 HP High pressure

37 HT Hot tank

38 HTF Heat transfer fluid

39 HX Heat exchanger

40 IHX Indirect heat exchanger

41 LCF Low Cycle Fatigue

42 LP Low pressure

43 PB Power block 
44 PI Proportional-Integral

45 PTPP Parabolic trough power plant

46 RH Re-heater

$47 \quad$ SF $\quad$ Solar field

48 SGS Steam generator system

49 SH Super-heater

50 SM Solar multiple

51 ST Steam turbine

52 TES Thermal Energy Storage

53 Symbols

54 ITD Inlet Temperature Difference

$\left[{ }^{\circ} \mathrm{C}\right]$

$55 \quad \dot{m} \quad$ Mass flow $\quad[\mathrm{kg} / \mathrm{s}]$

$56 \mathrm{p} \quad$ Pressure [bar]

$57 \quad \mathrm{~T} \quad$ Temperature $\quad\left[{ }^{\circ} \mathrm{C}\right]$

$58 \mathrm{t} \quad$ Time $\quad$ [s]

$59 \quad v_{\mathrm{T}} \quad$ Allowable ramp-up rate/heating rate

$[\mathrm{K} / \mathrm{min}]$

\section{Subscripts}

61 f fluid

$62 \max$ maximum

63 min minimum 


\section{Introduction}

Concentrated solar power plants (CSPPs) are becoming more common in the renewable energy market. This trend is expected to rise in the upcoming years due to their key capability of being integrated with relatively cheap thermal energy storage (International Energy Agency, 2014). This feature makes it possible to decouple the energy generation from the solar input, making the power they can generate available at any time (Guedez et al., 2017). However, despite this characteristic feature, CSPPs are not currently designed for continuous operation, therefore they still experience daily start-ups and shutdowns. In order to maximize their performance from both technical and economical standpoints, increasing the flexibility of their dynamic performance is an important aspect which must be addressed (Topel et al., 2017). The rate at which a power plant can start up is limited by thermo-mechanical constraints, which may increase the time to reach the nominal load of the power plant. The receiver, the steam turbine and the steam generator system (SGS) are usually the most limiting components in this regard. While the receiver (Samanes and Garcia-Barberena, 2014) and steam turbine (Topel et al., 2017) have been examined in the literature, the steam generator has not been the focus of many studies .

Many CSPPs in use today have steam generators which were typically designed as conventional heat exchangers, not optimised for transient applications (Vant-Hull, 2012). As the industry mainly used designs from conventional power plants, their SGS responded inefficiently to sudden changes in incident solar radiation and equally poorly to repeated morning start-ups. This can cause failures in the component due to excessive thermal stresses, which may compromise the economic viability of the power plants. Although the industry is interested in optimising SGS designs for CSPPs (Pelagotti et al., 2014), there is little information on optimal heating rate requirements. In order to maximize the flexibility (i.e. to increase the responsiveness of the power plant to a change in the power load or in insolation), and both the peak and the baseline rate of electric power production, it is essential that all the components are able to start as quickly as possible and enable the CSPPs to quickly start harvesting the incoming solar radiation. On the other hand, there might be limiting factors for one component, which might reduce the required heating rate for another. For example, if the receiver or solar field are the limiting factors, there is no need for the SGS to be able to start up at a faster rate than that of the solar field (Ferruzza et al., 2017). 
The SGS and steam turbine both start up at a rate that is governed by the need to limit thermal stresses and low-cycle fatigue (LCF) (Pelagotti et al., 2014; Topel et al., 2017). Thick-walled components, material properties and temperature gradients are the limiting factors. In the case of the steam generator, the main constraining factors are the maximum allowable stresses in thick walled components such as the steam drum, super-heater headers and T or Y junctions in the steam pipelines (Dzierwa and Taler, 2014; Taler et al., 2015). Typically, the limiting component is the evaporator drum, which is designed as a large diameter high pressure vessel, which must consequently have thick walls. The start-up procedure of the component is intended to reach nominal conditions for temperature, pressure and mass flow rates as rapidly as possible. In the case of the steam turbine, the shaft seal and blading clearances determine the maximum allowable thermal expansion of the components, while the shaft thickness is the limiting factor for thermal stress. As a general rule, the starting procedure of a steam turbine can be considered to have three different phases: pre start-up heating, rolling up and loading up. During this procedure, the key parameter which limits the heating rate is the difference in temperature between the incoming steam and the metal of the turbine. In order to avoid excessive thermal stresses in this component it is desirable to keep the temperature difference as low as possible (Spelling et al., 2012).

In previous studies, much attention is given to the thermal stress that limits the maximum heating rates of these components, but little information is available about their impact on the performance of the overall power plant. For instance, González-Gómez et al. (2017) analysed the thermo-mechanical stress in the case of SGS for solar applications, but the study was performed at component level, without considering the impact of such limitations on the performance of the power plant. The author also focused on design and cost-based optimization of such components without considering the system perspective.

The abovementioned studies considered the limitation regarding either the steam generator or the turbine, without addressing the interaction between the two (Dzierwa et al., 2016; Dzierwa and Taler, 2014; Taler et al., 2015). It is of crucial importance to evaluate how much different constraints on the start-up procedures of CSPPs affect their electric power production and whether significant differences occur under different conditions. This information will indicate where to improve the operation of the power plant and the design specifications for the components, from a thermo-mechanical point of view. Lastly, the operational strategy of the power plant determines the number of start-ups and their typology (hot, warm or cold start-ups) (Guedez et al., 2017; Spelling et al., 2012). For instance, if a CSPP operates 
purely in solar-driven without fuel back-up, its start-up would mainly occur in the morning when the sun is still rising. On the other hand, if a power plant is designed to work in peak load during a particular time of the day (e.g. during evening hours, when the price of electricity is higher), the start-up would occur when solar radiation or heat from the storage are readily available. From a start-up perspective (in the absence of back-up fuels), this would mean different availability of heat input, hence different start-up constraints.

The dynamic performance of parabolic trough power plants has been analysed previously (Almasabi et al., 2015; Blanco et al., 2011; Conrado et al., 2017; Luo et al., 2015), although the models proposed deal only with validation of the detailed component modelling of the solar field. Blanco et al. (2011) presented a model of a parabolic trough power plant (PTPP) and validated it against experimental data, but in this case the model of the power block was developed with a simplified correlation. Another approach was presented by Abed et al. (2016), in which a detailed dynamic model in APROS (Advanced Process Simulation Software) was validated against the operational data of Andasol II. The focus of the study was to develop a detailed control strategy of the power plant by means of PI (Proportional-Integral) controllers. The model presented did not focus on yearly performance but on daily control. None of these studies considered start-up constraints due to thermo-mechanical limitations. In previous works such constraints were usually analysed from a component perspective. For instance, Pelagotti et al. (2014) described in detail a dynamic model of a steam generator, and carried out a low-cycle fatigue analysis. The authors predicted the impact on the annual electricity production of PTPPs. Their calculations did not take into account start-up schedules of steam turbines or rates of heat availability, nor yearly performance evaluation of such power plants. A previous work by the authors (Topel et al., 2015) considered the impact of the start-up rate of the steam turbine for solar tower direct steam generation; however, in this work the start-up constraints of the steam turbine were not coupled with SGS constraints.

This paper presents an analysis of the effects of the thermal stress limitations of the steam generator and steam turbine on the power plant start-up, and quantifies their impact on the economy of the system. The study was performed for both solar-driven and peak-load conditions to emphasize on how different constraints on starting up a steam generator have different impacts on the electric power production and depend on how the plant is operated (Guedez et al., 2017). The paper also considers how differently sized 
solar fields (in terms of solar multiple) affect the impact of the steam turbine and steam generator constraints from an operational perspective.

In section 2 the paper presents the approach used for modelling the power plant. Secondly, it summarizes the main limitation for the start-up of the steam generator and turbine and how such constraints were implemented in the control logic for the overall model. In section 3, it presents the evaluation of the impact of the constraints of the steam generator on the electric power production both in peak-load and solar-driven together with a discussion on the results. Lastly section 4 outlines the conclusions and final remarks.

\section{Methods}

Modelling was performed in DYESOPT, an in-house tool developed at KTH, Royal Institute of Technology, Stockholm, which was developed for techno-economic modelling of CSP plants (Guedez et al., 2017). The tool has been validated against Thermoflex, a commercially available software for power plant performance estimation (Thermoflow, 2014), demonstrating a relative deviation between the results of two software below $10 \%$ in the case considered. As may be seen in Figure 1, the tool allows for both steady-state design and dynamic simulation, and can make techno-economic calculations for different assumed locations for the plant. The overall approach, as shown in Figure 1, can be linked to a multiobjective optimizer (Guedez et al., 2017).

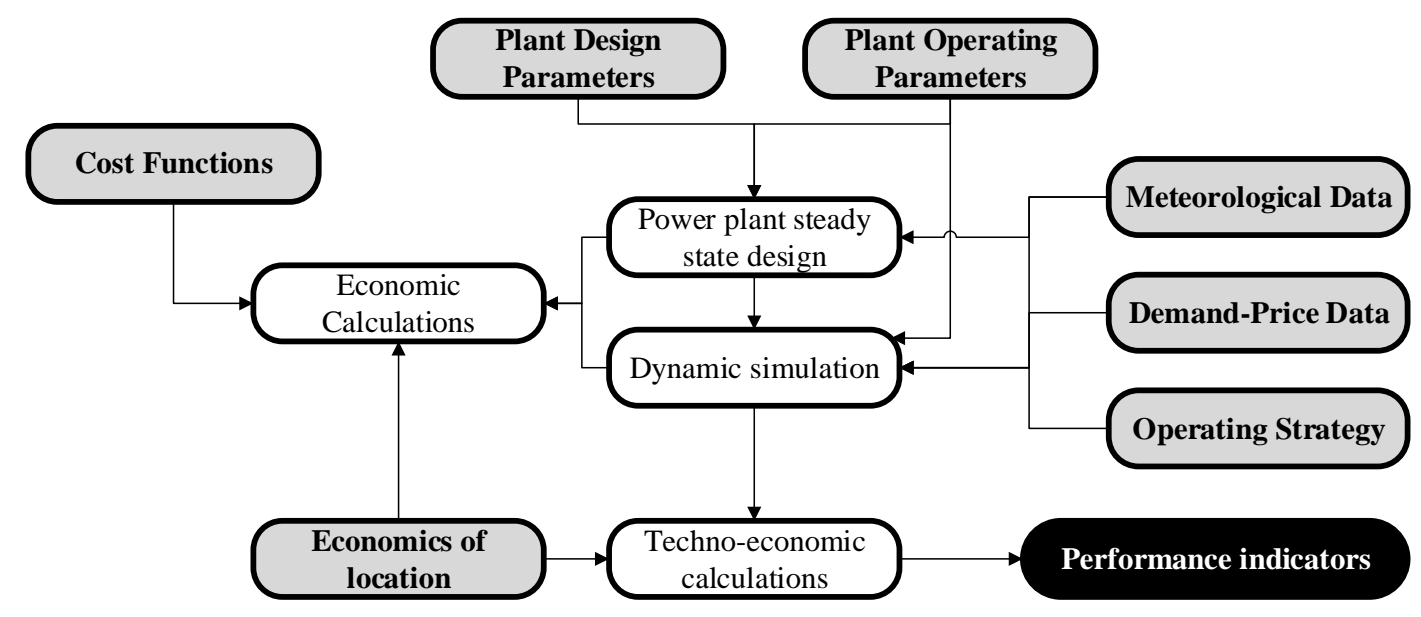

Figure 1: DYESOPT workflow diagram.

The model of the PTPP was implemented in the tool and validated as described in Ferruzza et al., (2015).

The author implemented the parabolic trough sizing methodology and the TRNSYS model in DYESOPT and validated against data available in literature with a maximum error of $-8.9 \%$ (Ferruzza et al., 2017). 
The model was further developed by including different operating strategies and the option of including an air-cooled condenser (ACC). The consideration of ACCs is of topical interest, as many plants that are currently under development or in the tender phase will be placed in desert areas. Having no direct access to cooling water mandates the use of ACC in which the condensation of steam is achieved solely by air cooling and parasitic electrical power consumption (Moore et al., 2013). The ACC model was previously validated by Guedez et al. (2017).

\subsection{Steam generator start-up limitations}

The start-up procedure for a steam generator consists of bringing temperature, pressure and mass flow rate to nominal values in each component of the system. As noted above, the rate at which this can be done is highly dependent on thermo-mechanical limitations that are determined by their materials and geometry. Previous studies have shown that the main limiting components during an SGS start-up are the evaporator and super-heater, hence these two were considered in detail in the present study (Basaran, 2015; Taler et al., 2015). Another constraint which must be addressed is the occurrence of thermal shocks that might occur if the HTF temperature is higher than the metal temperature by more than a critical amount, as the material could then experience cracking and ultimately failure (Price, 2017). A limit on the maximum allowable temperature difference is usually implemented in the control logic of the start-up operation. Even though the minimum and maximum heating rates $\mathrm{v}_{T \min }$ and $\mathrm{v}_{\mathrm{T} \max }$ for the required pressure can be determined according to the norm DIN EN 12952-3 (CEN, 2012), the goal of the present study is to determine the optimal range of values from a system perspective. The heating rates used to calculate the permitted fluid temperature change were obtained using the following equation (Taler et al., 2015):

$$
\frac{d T_{\mathrm{f}}}{d t}=\frac{p_{\max } v_{\mathrm{T}_{\min }}-p_{\min } v_{\mathrm{T}_{\max }}}{p_{\max }-p_{\min }}+\frac{v_{\mathrm{T}_{\max }}-v_{\mathrm{T}_{\min }}}{p_{\max }-p_{\min }} p\left(T_{\mathrm{f}}\right)
$$

These equations express the rate at which the fluid temperature $\left(T_{\mathrm{f}}\right)$ can change depending on the pressure of the fluid (minimum $\left(p_{\text {min }}\right)$ and maximum $\left.\left(p_{\max }\right)\right)$ and the minimum and maximum heating rates which are dependent on the geometry, material properties and operating temperature and pressure. In an evaporator, the water is at saturation point so the pressure and temperature are related. As a consequence, the temperature of the fluid will be dependent on the pressure, and Equation (1) can be solved using a 
Runge-Kutta method, assuming $T_{\mathrm{f}}(\mathrm{t}=0)=T_{0}$. In the case of the super-heater, the fluid is not at saturation conditions, the pressure is a function of time and determined by the evaporator conditions.

Simulations were carried out for different constraints on the evaporator and the super-heater. As discussed by the authors in Ferruzza et al. (2015), an optimal heating rate constraint can be found for the superheater by assuming that it is 1.8 times higher than the evaporator limit. However, simulations were also carried out using a 1.1 multiplier, to demonstrate the impact of this value and show how sensitive the results are to this design parameter. Two main start-up schedules can be identified for the evaporator. In the case of an evaporator with a drum configuration (natural or forced circulation), the minimum allowable pressure of the steam turbine can be maintained overnight. Such a start-up routine will be termed a hot start-up. However, when this is not possible (absence of steam drum or pressure vessel), the pressure would not be maintained overnight and the evaporator would have to start up from ambient pressure conditions. This will be termed a cold start-up. In order to study how different heating rate routines will affect the start-up of the power plant, both hot and cold start-ups were included, making the assumption that the overnight heat losses from the steam drum will be negligible. Observations from existing power plants indicate that the overnight heat losses from the steam drum may be neglected due to the large mass of water containing a high thermal inertia and experiencing a limited temperature drop.

\subsection{Steam turbine start-up schedule}

As for the SGS, the steam turbine start-up procedure is limited by the permissible temperature difference between the metal surface and the steam. Different start-up schedules are defined by the manufacturer based on the initial temperature of the turbine metal (or stand still time). The start-ups procedures are classified as cold, warm or hot. A hot start-up would take only 8-10\% of the time it takes for a cold startup, while a warm start-up would take $45-50 \%$ of that of a cold start-up (Topel et al., 2015). Figure 2 illustrates the three different start-up curves. The start-up procedure involves two phase which are denoted for the cold case as the A-B and B-C lines which represent the rolling up and loading up of the turbine, respectively (Topel et al., 2015). 


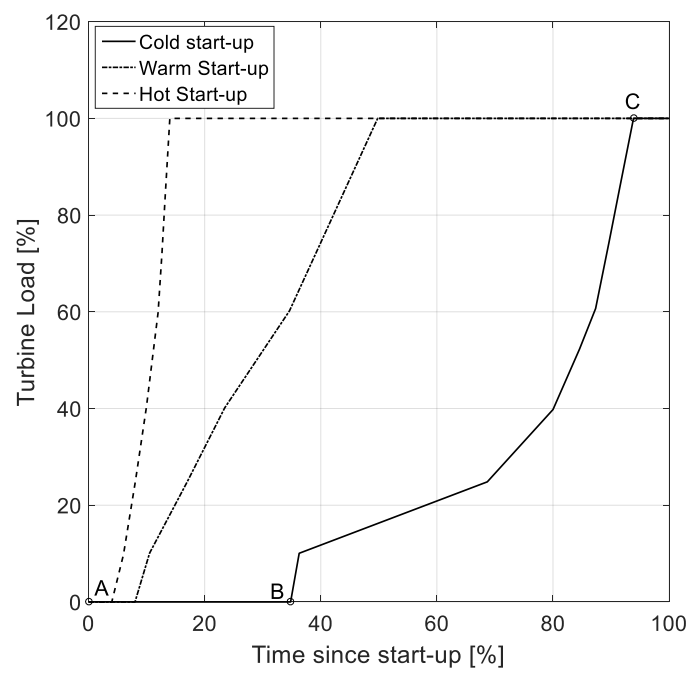

Figure 2: Cold, warm and hot steam turbine start-ups (Adapted from Topel et al., (2015)).

The start-up schedules were kept constant in order to focus mostly on the impact of the steam generator on the overall performance of the power plant. The minimum allowable pressure was kept at 35 bar (as by requirement of the steam turbine) and the rate at which pressure, mass flow rate and temperature could rise were determined following the paper by. Schenk et al., (2015). During the running-up the mass flow rate is kept at $5 \%$ of the nominal value, while during the loading up the mass flow rate increases with a rate determined directly by the steam turbine start-up routine depending on the metal temperature at which the procedure begins. The different hot, warm and cold start-up curves presented in Figure 2 were introduced in the model, depending on the metal temperature (Topel et al., 2015).

\subsection{Power plant modelling}

The plant layout considered in the paper is shown in Figure 3. The thick lines represent the HTF loop, which is heated up by the parabolic trough (PT) mirrors, and either fed directly to the steam generator (comprising an economizer (ECO), evaporator (EVA), super-heater $(\mathrm{SH})$ and re-heater $(\mathrm{RH})$ ) or to heatup, through the indirect heat exchanger (IHX), the salts from the cold tank (CT) which are then pumped to the hot tank (HT). The other cycle represents a conventional Rankine-reheat cycle with high pressure (HP) and low pressure (LP) steam turbines (ST) an air-cooled condenser (ACC) and a deaerator (D). The power plant was designed for the location of Seville, Spain, with a power output of $55 \mathrm{MWe}$ gross, according to Guedez et al. (2017) for the power block, Gilman et al. (2008) for the HTF cycle Lippke (1995) and Dudley (1994) for the solar field. Firstly, the Rankine cycle was designed for the chosen gross 
power, determining its efficiency and thermal input requirement. The size of the solar field was determined accordingly and scaled considering the solar multiple (SM). Lastly, the thermal energy storage (TES) mass was calculated to ensure the amount of hours desired to satisfy the thermal demand of the power block. The design methodology was implemented in Matlab, while the yearly performance dynamic model was developed in TRNSYS (University of Wisconsin Madison, 1975) in order to be implemented in DYESOPT.

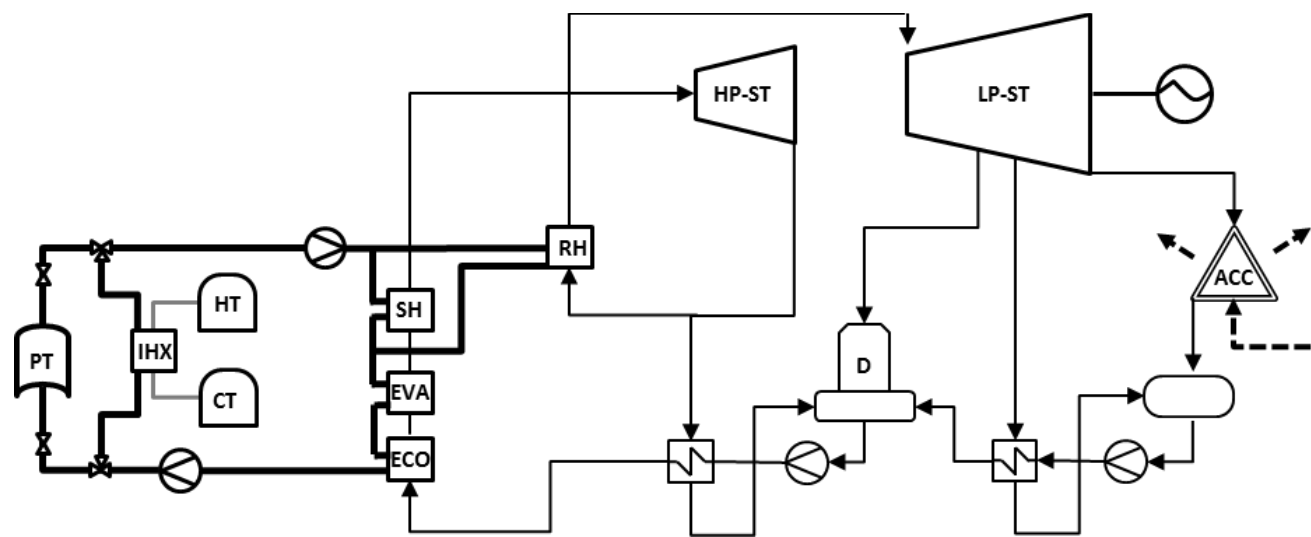

Figure 3: Layout of the considered parabolic trough power plant integrated with indirect thermal energy storage and air cooled condenser.

The dynamic model of the power plant was integrated with a controller, which ran the start-up procedure and applied the constraints to the steam generator and turbine. The logic of the controller is shown in Figure 4. A similar strategy was applied when the power plant was operating either in solar-driven or peak-load. In solar-driven, the start-up will occur in the morning as soon as the solar heat is available. In this case, both the thermal shock and the thermal stresses (in the form of heating rates) are calculated and a required HTF temperature is sent to the solar field. Afterwards, the steam temperature and pressure rise accordingly, until the minimum allowable condition for superheated steam is reached. At this point the steam turbine can start according to the start-up procedure. Similarly, for peak-load operation, the heating rate constraints are calculated, from which a HTF temperature is obtained. However, as the plant operates at specific times of the day, an optimal design is supposed to ensure that there is heat available to be extracted from either the solar field or the thermal storage hot tank. If the thermal storage is used, the oil temperature can be regulated by adjusting the salt mass flow rate. If HTF temperatures higher than the allowable SGS HTF temperature occur, an attemperator may be used to reduce the temperature of the thermal oil or the HTF may be mixed (if possible) with oil at a lower temperature, either from the solar field loop or the SGS return line. One of the key differences between the two operation modes is the fact 

the solar field.



Figure 4: Control logic for the power plant during start-ups.

261 Once both the turbine and the steam generator have reached nominal operating conditions, the start-up procedure is finished and the power plant enters daily operation. Part-load operation is taken into account according to DLR (2006), if nominal heat input is not reached at the steam generator. The strategy depicted in Figure 4 is applicable in both peak-load and solar-driven operation mode. Table 1 summarizes the conditions for the two operational modes following Guedez et al. (2017).

Table 1: Summary of operation modes

\begin{tabular}{ll}
\hline Operation mode name & Condition \\
\hline Solar-driven & Whenever radiation or TES are available \\
Peak-load & Only between 15-21 if heat input is available \\
\hline
\end{tabular}

The main design parameters and thermal performance indicators are listed in Table 2. It summarizes both the parameters which were considered fixed and the ones that were allowed to vary for the purpose of the analysis. The PTPP designed according to Table 2 served as a basis for an analysis of the impact of the constraints. The SM and TES size for the peak-load case were chosen following Guedez et al. (2017). In 
the solar-driven case the SM was varied to account for the impact of the solar field size while the TES was kept at $10 \mathrm{~h}$ as this was a size that would still require warm turbine start-ups while allowing the plant to operate in the evening even in winter periods. The 15-21 time operation was chosen according to Guedez et al. (2017). However, in Guedez et al. (2017) the price of electricity in the suggested location was higher than zero even between 5 and 17 . The study considered only peak price hours, in order to remove the influence of the solar field on the SGS. This means that the heat provided to the steam generator comes directly either only from the TES or from the combination of the TES and SF, in case it cannot come directly from the solar input. If the DNI is high enough the PT has already gone through its start-up phase and could potentially provide nominal heat input to the steam generator. This makes it possible to focus on how the constraints of the evaporator and super-heater affect the performance of the power plant if electricity production was postponed to a particular time of the day.

Table 2: Summary of design parameters

\begin{tabular}{llll}
\hline Operation mode name & Units & Peakload case & Solar-driven case \\
\hline SM & {$[-]$} & 1.1 & $1.5-3$ \\
Gross Power & {$[\mathrm{MW}]$} & 55 & 55 \\
TES capacity & {$[\mathrm{h}]$} & 5 & 10 \\
Inlet HP/LP pressure & {$[\mathrm{bar}]$} & $100 / 16.7$ & $100 / 16.7$ \\
Nominal condensing pressure & {$[\mathrm{bar}]$} & 0.06 & 0.06 \\
SF HTF maximum temperature & {$\left[{ }^{\circ} \mathrm{C}\right]$} & 393 & 393 \\
Nominal turbine inlet temperature & {$\left[{ }^{\circ} \mathrm{C}\right]$} & 378 & 378 \\
\hline
\end{tabular}

\section{Results and discussion}

The impact of the start-up constraints was investigated and the performance of the power plant under different limitations is presented in this section. Both peak-load and solar-driven operation were analysed. For both of these modes, the start-up constraint of the steam generator was analysed for the cases shown in Table 3.

Table 3: Summary of the respective parameters for the four different cases analyzed.

\begin{tabular}{lllll}
\hline Case Name & Case $1 \mathrm{a} / \mathrm{b}$ & Case 2 a/b & Case 3 a/b & Case $4 \mathrm{a} / \mathrm{b}$ \\
\hline Average evaporator heating rate $[\mathrm{K} / \mathrm{min}]$ & $3-12$ & $3-12$ & $3-12$ & $3-12$ \\
Super-heater heating rate multiplier $[\mathrm{K} / \mathrm{min}]$ & $1.1 / 1.8$ & $1.1 / 1.8$ & $1.1 / 1.8$ & $1.1 / 1.8$ \\
Start pressure $[$ bar] & 35 & 1 & 35 & 1 \\
Thermal shock $\Delta \mathrm{T}[\mathrm{K}]$ & 63 & 63 & 63 & 63 \\
Operation strategy & peakload & peakload & solar-driven & solar-driven \\
\hline
\end{tabular}


generator system based on a kettle-reboiler type evaporator (González-Gómez et al., 2017). The higher threshold was chosen as a potential improvement compared with the designs of header and coil geometrical configurations already available in industry (Aalborg CSP, 2015). The cases are also considering different start-up strategies for the steam generator. If a hot start-up is available (Case 1 and Case 3 respectively), it means that the minimum allowable pressure of the turbine is kept at the steam drum. In the case of a cold start-up (Case 2 and Case 4 respectively), the pressure starts from ambient conditions.

\subsection{Peak-load case}

Figure 5 shows the results of the impact of the SGS heating rate constraints on the yearly electricity production for the cases presented in Table 3. The graph indicates that for a hot start-up, the potential improvement in Case 1 is $1.54 \%(0.9$ GWhe) for Case 1a. For cold start-ups of the evaporator, the potential increases to $12.5 \%$ (6.3 GWhe). Higher impacts were found for Cases $1 \mathrm{~b}$ and $2 \mathrm{~b}$, when lower SH heating rate multipliers were chosen, the potential for improvement being as high as $3.6 \%$ and $25 \%$. In the first cases, the evaporator was the main limiting factor during the start-up, while in the latter the limitations imposed on the super-heater delayed the initial phase of the turbine start-up, making the impact of the procedure more significant in terms of electricity production. These findings demonstrate the importance of a properly designed and operated super-heater while starting up the SGS. The results of Case 1a suggest that for hot evaporator start-ups it is possible to identify an optimal range of heating rate constraints around 7-8 K/min. Beyond this threshold, no significant increase in power production was observed, making it unnecessary to go above this design point. This is mainly due to the fact that even though the SH could reach its nominal operating condition at faster rates, the turbine would still have to be operated so as to respect its thermal limitations. This underlines how significant it is to consider both components when optimising the total system design to respect thermo-mechanical constraints. If a faster start-up rate was achievable for the steam turbine, then higher start-up constraints would be required for the steam generator. For a cold start-up of an evaporator, higher start-up rates would always imply greater electricity production for both a slow and a fast super-heater. In fact, the pressure that could be maintained overnight was well below the minimum allowable pressure for the steam turbine, requiring that SGS covers a larger temperature gradient, in turn postponing the beginning of the steam turbine start- 


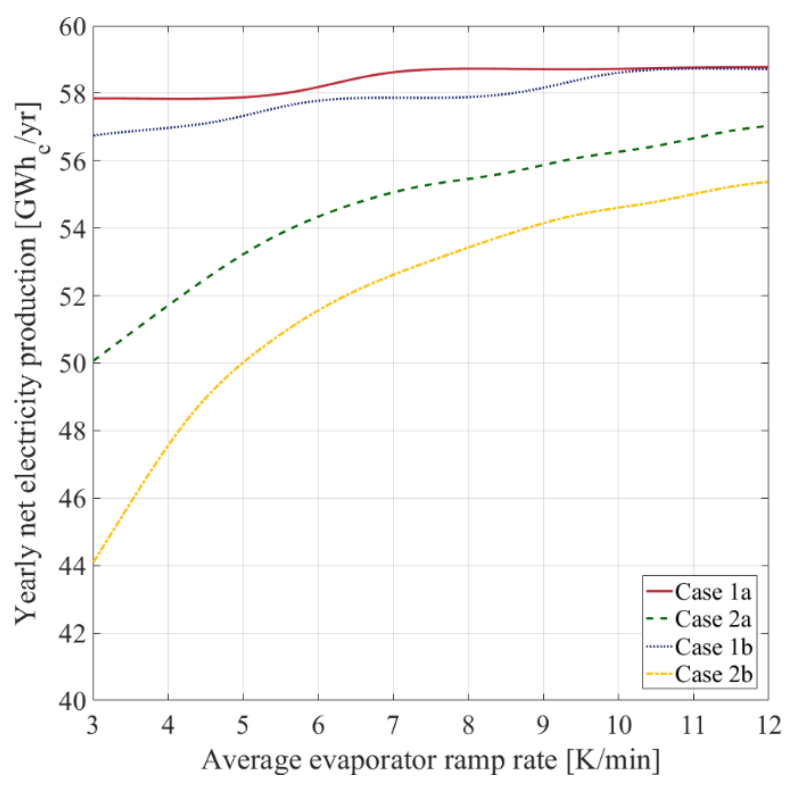

Figure 5: Impact of the evaporator heating rate constraints on the net electricity production for a peakload operating strategy.

317 Figures $6 \mathrm{a}$ and $6 \mathrm{~b}$ show respectively the steam temperature during a two day period and the net electricity output for case 1a. The two different lines refer to a slow (3 K/min) and a fast (12 K/min) SGS 319 configuration. Figures $7 \mathrm{a}$ and $7 \mathrm{~b}$ show the same variables but for case 2a. The results illustrated in Figure 5 may better understood by looking at Figures 6 and 7. In the first two, it may be seen that even if the evaporator start-up rate is 4 times higher than in the slow case, the impact on the net power output is barely noticeable (a close up is shown in the left part of the graph). This means that every day the beginning of the steam turbine start-up procedure is delayed by 6 minutes. In case 2, on the other hand, if the steam pressure is not maintained overnight, the delay is more significant and observable. In this case the steam turbine would experience a delay of as much as 30 minutes, making the SGS a bottleneck for the start-up procedure. These considerations indicate that the presence of a pressure vessel (in the form of a steam drum in this case) is important, to make the start-up procedure as effective as possible. 

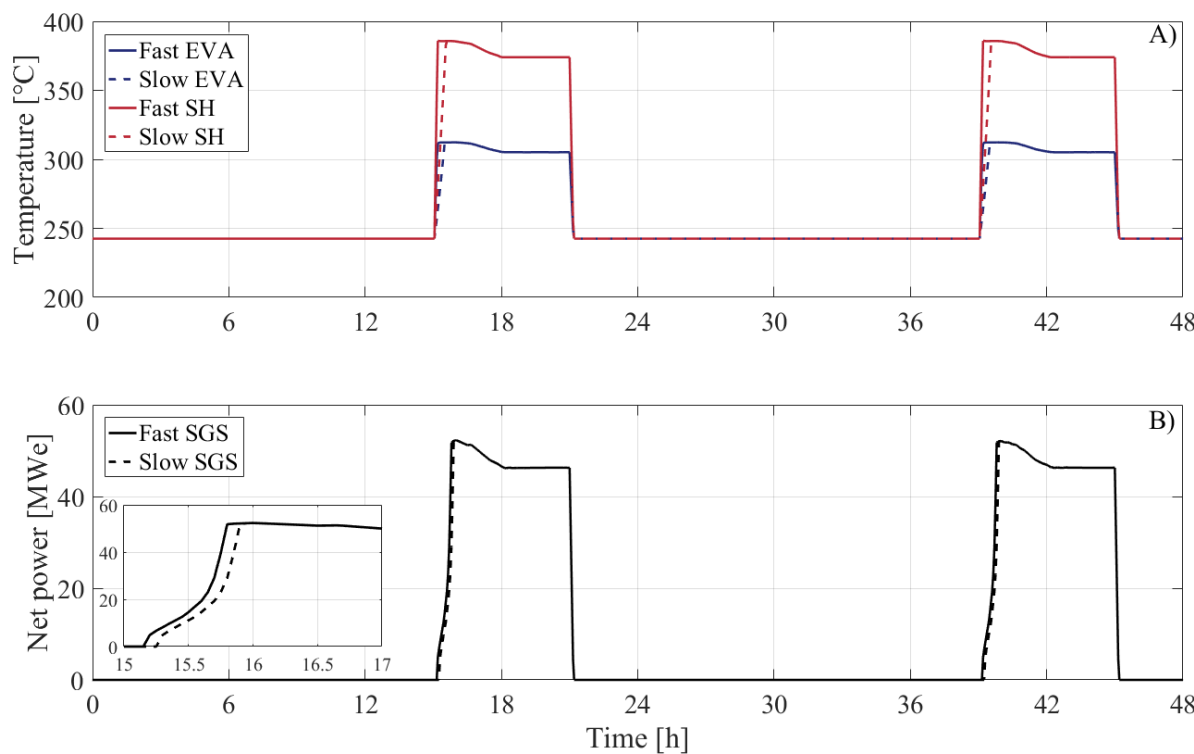

Figure 6: Comparison of a two-day performance between a slow and a fast evaporator during a hot start-up for a peak-load operating strategy case. A) Evaporator and superheater temperatures, B) Net power output.
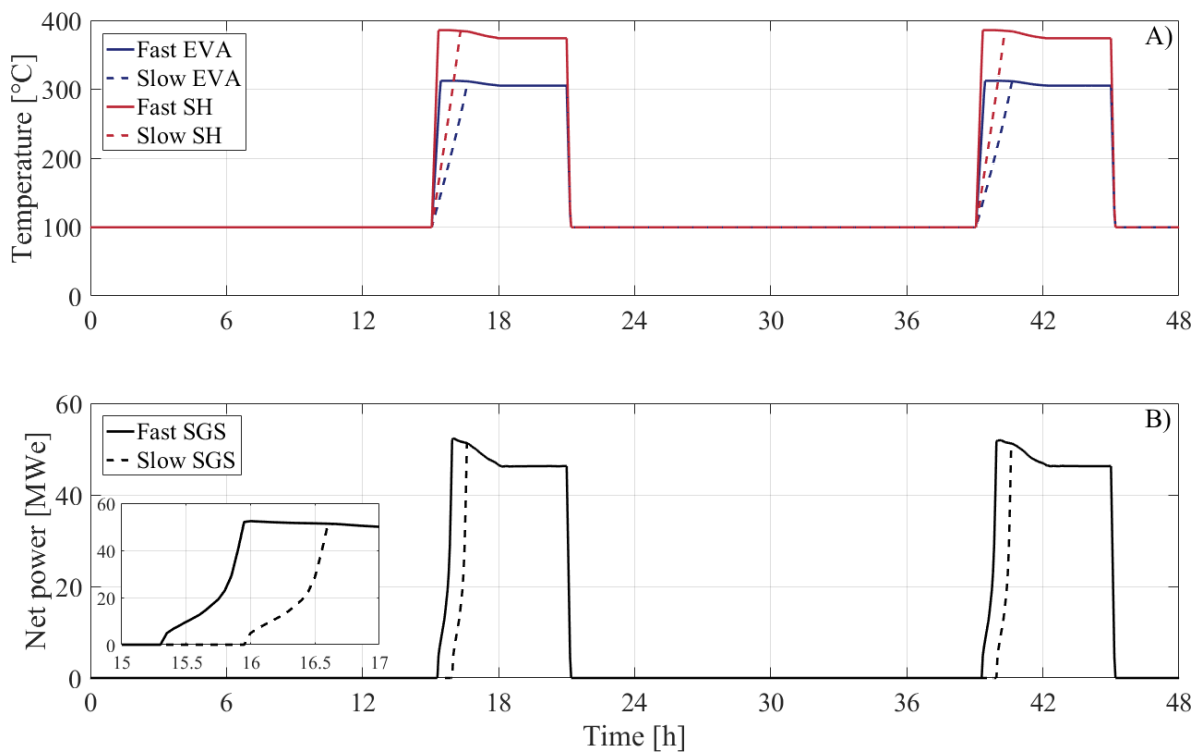

Figure 7: Comparison of a two-day performance between a slow and a fast evaporator during a cold start-up for a peak-load operating strategy case. A) Evaporator and superheater temperatures, B) Net power output. 
Figure 8 illustrates an analysis similar to the one described in section 3.1 but for a solar-driven operational strategy. The reference case adopted was for a SM equal to 2, being a representative value for existing power plant configurations like Andasol (Ferruzza et al., 2017). Following a similar consideration as before, if only hot evaporator start-ups are considered, the results indicate that the potential for improvement of the net electricity production is as low as $0.27 \%(0.56 \mathrm{GWhe})$, while for cold start-ups, this impact increases to a maximum of $2.3 \%$. As in the previous case, if the super heater is not operated or designed optimally, the maximum potential improvement is $4.65 \%$ for cold start-ups.



Figure 8: Impact of the evaporator ramp rate on the net electricity production for a solar-driven operating strategy case, considering a solar multiple equal to 2 .

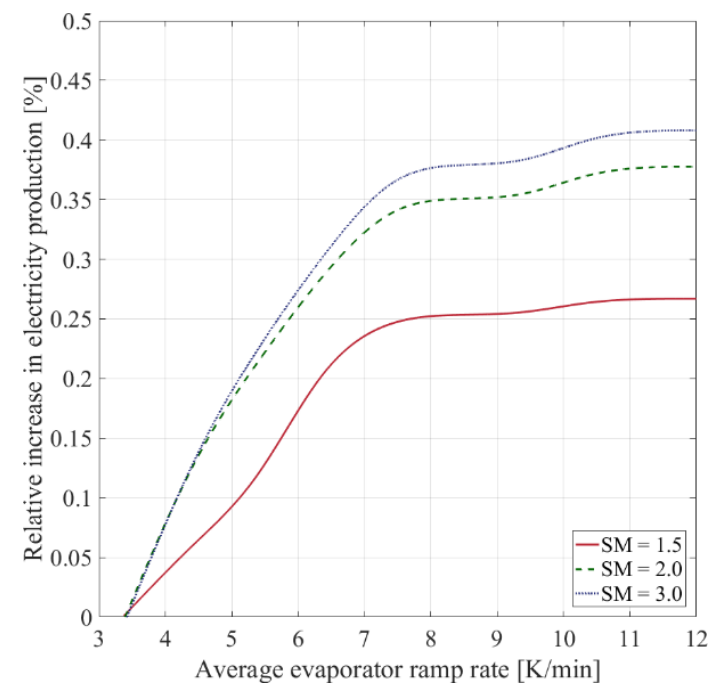

Figure 9: Sensitivity to the solar field size on the impact of the evaporator ramp rate constraints for a solar-driven operating strategy case.

Figure 9 illustrates the relative increase in electricity production for different Solar Multiple (SM) cases.

The figure suggests that the impact of the start-up constraints on the steam generator is considerably affected by the size of the solar field. It may be seen that by doubling the size of the solar field from a SM of 1.5 to 3.0 , the relative increase can be improved from a maximum of $0.28 \%$ to $0.41 \%$. However, the impact is not very important in the economy of the power plant. Figure 10 illustrates the development of the solar field thermal output and thermal input to the SGS and may suggest some reasons for this low improvement. The close-up in the figure shows that in the morning, the heat input to the SGS follows the 



Figure 10: Comparison of a two-day performance between a slow and a fast evaporator during a hot start-up for a solar-driven operating strategy case. A) Thermal power at solar field and input to the steam generator system, B) Evaporator and Super-heater temperatures

The pressure at the SGS follows a similar trend, as it is proportional to the heat input to the evaporator.

Hence the start-up at the evaporator is no longer limited by its thermo-mechanical constraints but more by the heat available from the solar field. This is directly shown in in the lower part of Figure 10. It may be seen that in both the slow and fast cases, the temperature at the evaporator (and therefore the pressure, as it is at saturation point), are not two separate lines but they overlap. The only limiting component from a thermo-mechanical standpoint is therefore the super-heater, resulting in only negligible differences in power production. In these cases the steam reaches the minimum allowable conditions at a later stage, delaying the start-up of the turbine.

\section{Conclusions}

A detailed analysis was used to illustrate the impact of the SGS constraints during the start-up procedure of a PTPP. To achieve this, an existing detailed model of a PTPP that had previously been developed by the authors was extended to allow the simulation of two different operating strategies, namely peak-load and solar-driven operation. The model was also extended by the addition of an air-cooled condenser. A simulation tool was used to apply the start-up constraints of both the steam generator and the turbine. The 
model was integrated with an existing tool for the dynamic performance evaluation of power plants (DYESOPT).

The results suggest that for peak-load operation, by changing the constraints of the steam generator from $3 \mathrm{~K} / \mathrm{min}$ to $12 \mathrm{~K} / \mathrm{min}$, the potential improvement in total net electricity output is $1.5 \%$. It was shown that being able to maintain the minimum allowable turbine pressure overnight would be highly beneficial as it makes it possible to start the steam turbine in the most efficient way. The optimal range of maximum allowable heating rate for the evaporator was found to be about 7-8 K/min, designing a component with higher constraints would provide no benefit for the economy of the power plant. For solar-driven operation, the results indicate that for a solar field design with a SM equal to 2, the potential improvement of electricity production is as low as $0.27 \%$. This figure might increase if the SF is further oversized, but only to $0.41 \%$. The main limiting factor during start-ups is the amount of heat available in the solar field. As the solar field can only provide nominal operating power to the SGS after 1 hour, the pressure at the evaporator cannot achieve its nominal value before that time, so the heating rate will be slower than the maximum limits in most start-up procedures. As a general conclusion, the results indicate that raising the maximum allowable evaporator constraints would not proportionally increase the yield of the power plant, as their effect is limited, either by other constraints at the steam turbine or at the solar field. It is therefore clear that the interaction among the three components is crucial when optimising the thermomechanical design of an SGS. 
Abed, W., Al-maliki, K., Alobaid, F., Kez, V., Epple, B., 2016. Modelling and dynamic simulation of a parabolic trough power plant. J. Process Control 39, 123-138. https://doi.org/10.1016/j.jprocont.2016.01.002

Almasabi, A., Alobaidli, A., Zhang, T.J., 2015. Transient characterization of multiple parabolic trough collector loops in a 100 MW CSP plant for solar energy harvesting. Energy Procedia 69, 24-33. https://doi.org/10.1016/j.egypro.2015.03.004

Basaran, I., 2015. A Comprehensive Study of the Imposed Limitations on Concentrating Solar Power Plant Start-up Speeds. MSc, Thesis. Royal Institute of Technology (KTH), Stockholm.

Blanco, D., Luis, A., Garc1, I.L., 2011. Performance model for parabolic trough solar thermal power plants with thermal storage : Comparison to operating plant data. Sol. Energy 85, 2443-2460. https://doi.org/10.1016/j.solener.2011.07.002

CEN, 2012. Water-tube boilers and auxiliary installations - Part 3: Design and calculation for pressure parts of the boiler. Brussels.

Conrado, L.S., Rodriguez-pulido, A., Calderón, G., 2017. Thermal performance of parabolic trough solar collectors. Renew. Sustain. Energy Rev. 67, 1345-1359. https://doi.org/10.1016/j.rser.2016.09.071

DLR, 2006. A TRNSYS Model Library for Solar Thermal Electric Components ( STEC ), Reference manual.

Dudley, V., 1994. SEGS LS-2 Solar Collector. Test Results. Sandia National Laboratories. Albuquerque, New Mexico.

Dzierwa, P., Taler, D., Trojan, M., Taler, J., 2016. Evaporator Heating with Optimum Fluid Temperature Changes. Procedia Eng. 157, 29-37. https://doi.org/10.1016/j.proeng.2016.08.334

Dzierwa, P., Taler, J., 2014. Optimum Heating of Pressure Vessels With Holes. J. Press. Vessel Technol. 
Ferruzza, D., Topel, M., Basaran, I., Laumert, B., Haglind, F., 2017. Start-Up Performance of Parabolic Trough Concentrating Solar Power Plants, in: AIP Conference Proceedings 1850. pp. 1-9. https://doi.org/10.1063/1.4984542

Gilman, P., Laboratory, N.R.E., Laboratories, S.N., 2008. Solar advisor model user guide for version 2.0. Technical Report.

González-Gómez, P.Á., Gómez-Hernández, J., Briongos, J.V., Santana, D., 2017a. Thermo-economic optimization of molten salt steam generators. Energy Convers. Manag. · 146, 228-243. https://doi.org/10.1016/j.enconman.2017.05.027

González-Gómez, P.Á., Petrakopoulou, F., Briongos, J.V., Santana, D., 2017b. Steam generator design for solar towers using solar salt as heat transfer fluid, in: AIP Conference Proceedings. pp. 1-8. https://doi.org/10.1063/1.4984363

Guedez, R., Topel, M., Ferragut, F., Callaba, I., Perez-segarra, C.D., 2017. A Methodology for Determining Optimum Solar Tower Plant Configurations and Operating Strategies to Maximize Profits Based on Hourly Electricity Market Prices and Tariffs. Sol. Energy Eng. 138, 1-12. https://doi.org/10.1115/1.4032244

International Energy Agency, 2014. Technology Roadmap, Solar Thermal Electricity. Paris.

Lippke, F., 1995. Simulation of the Part-Load Behavior of a 30 Mwe SEGS Plant. Report. Sandia National Laboratories. Albuquerque, New Mexico.

Luo, N., Yu, G., Hou, H.J., Yang, Y.P., 2015. Dynamic modeling and simulation of parabolic trough solar system, in: SolarPACES 2014. pp. 1344-1348. https://doi.org/10.1016/j.egypro.2015.03.137

Moore, J., Grimes, R., O’Donovan, A., Walsh, E., 2013. Design and testing of a novel air-cooled condenser for concentrated solar power plants. Energy Procedia 49, 1439-1449. https://doi.org/10.1016/j.egypro.2014.03.153 
Pelagotti, L., Sørensen, K., Condra, T.J., Joseph, T., Franco, A., 2014. Modelling of a Coil Steam Generator for CSP applications \$, in: Proceedings of the 55th International Conference on Simulation and Modelling.

Price, J.W.H., 2017. Thermal Shock Cracking : Design and Assessment Guidelines Thermal Shock Cracking : Design and Assessment Guidelines. J. Press. Vessel Technol. 129, 125-132. https://doi.org/10.1115/1.2389029

Samanes, J., Garcia-barberena, J., 2014. A model for the transient performance simulation of solar cavity receivers. Sol. Energy 110, 789-806. https://doi.org/10.1016/j.solener.2014.10.015

Schenk, H., Dersch, J., Hirsch, T., Polklas, T., 2015. Transient Simulation of the Power Block in a Parabolic Trough Power Plant. Proc. 11 Int. Model. Conf. 605-614. https://doi.org/10.3384/ecp15118605

Spelling, J., Jöcker, M., Martin, A., 2012. Annual performance improvement for solar steam turbines through the use of temperature-maintaining modifications. Sol. Energy 86, 496-504. https://doi.org/10.1016/j.solener.2011.10.023

Taler, J., Weglowski, B., Taler, D., Sobota, T., Dzierwa, P., Trojan, M., Madejski, P., Pilarczyk, M., 2015. Determination of start-up curves for a boiler with natural circulation based on the analysis of stress distribution in critical pressure components. Energy 92, 153-159. https://doi.org/10.1016/j.energy.2015.03.086

Thermoflow, 2014. Thermoflex Modular Program for Thermal Power Sys- tems [WWW Document]. URL www.thermoflow.com (accessed 11.22.17).

Topel, M., Genrup, M., Jöcker, M., Spelling, J., Laumert, B., 2017. Operational Improvements for Startup Time Reduction in Solar Steam Turbines. Sol. Energy Eng. 137, 1-8. https://doi.org/10.1115/1.4028661

Topel, M., Guédez, R., Laumert, B., 2015. Impact of Increasing Steam Turbine Flexibility on the Annual 

https://doi.org/10.1016/j.egypro.2015.03.196

University of Wisconsin Madison. Solar Energy Laboratory., 1975. TRNSYS, a transient simulation program. Madison, Wis. : The Laboratory, 1975.

Vant-Hull, L.L., 2012. Central tower concentrating solar power (CSP) systems, Concentrating Solar Power Technology: Principles, Developments and Applications. Woodhead Publishing Limited, Houston. https://doi.org/10.1016/B978-1-84569-769-3.50008-X

Aalborg CSP, 2015. Aalborg CSP Steam Generator. URL http://www.aalborgcsp.com/quickmenu/brochures/ (accessed 8.3.17). 